\title{
High-Density Lipoprotein Subclass Distribution in Premature Newborns before and after the Onset of Enteral Feeding
}

\author{
ORSOLYA GENZEL-BOROVICZÉNY, ARTHUR E. D'HARLINGUE, L. C. KAO, C. SCOTT, AND \\ TRUDY M. FORTE \\ Division of Neonatology, Children's Hospital, Oakland, California 94609 [O.G-B., A.E.D., L.C.K., C.S.] and \\ Donner Laboratory, Lawrence Berkeley Laboratory, University of California, \\ Berkeley, California 94720 [T.M.F.]
}

\begin{abstract}
Changes in high-density lipoprotein (HDL) subclass distribution were evaluated in a group of premature infants during the early postnatal period to ascertain whether enteral feeding brought about a rapid shift from neonatal to adult-like distributions. All infants were fed a combination of breast milk and formula. Cord blood of premature infants had a predominance of large, less dense $\left(\mathrm{HDL}_{2 \mathrm{~b}}\right)_{\mathrm{gge}}$ and a paucity of intermediate-sized $\left(\mathrm{HDL}_{3 \mathrm{a}}\right)_{\mathrm{gge}}$ particles. Lack of a peak in the $\left(\mathrm{HDL}_{3 \mathrm{a}}\right)_{\mathrm{gge}}$ is a characteristic feature for cord blood, whereas a prominent $\left(\mathrm{HDL}_{3 \mathrm{a}}\right)_{\mathrm{gge}}$ peak is characteristic of adult plasma. After the start of enteral feeding, blood was obtained at two timepoints: 6-14 days (sample A) and 17-32 days (sample B) postdelivery. With the onset of feeding, triglyceride increased significantly from an average of $34 \mathrm{mg} / \mathrm{dl}$ in cord blood to $120 \mathrm{mg} / \mathrm{dl}$ in sample $B$, and cholesterol increased from 86 to $112 \mathrm{mg} / \mathrm{dl}$ in the same period. Increases in plasma lipid concentrations were paralleled by a redistribution of subclasses such that three components of almost equal intensity were evident in sample $B$; these consisted of $\left(\mathrm{HDL}_{2 \mathrm{~b}}\right)_{\mathrm{gge}},\left(\mathrm{HDL}_{2 \mathrm{a} 2}\right)_{\mathrm{gge}}$, and $\left(\mathrm{HDL}_{3 \mathrm{~b}}\right)_{\mathrm{gge}}$. A paucity of $\left.\left(H_{D L}\right)_{3 a}\right)_{g g e}$ particles persisted even after onset of enteral feeding; thus, increases in plasma triglyceride and cholesterol per se are not sufficient to induce the adult-like distribution. It is suggested that development of the normal adult HDL subclass pattern is complex and is probably related to the development and interaction of several factors, including plasma enzymes involved in lipid hydrolysis and esterification, lipid exchange proteins, and hormonal status. (Pediatr Res 23:543-547, 1988)
\end{abstract}

\section{Abbreviations}

apo, apolipoprotein

CE, cholesteryl ester

CETP, cholesteryl ester transfer protein

FC, free cholesterol

gge, gradient gel electrophoresis

HDL, high-density lipoproteins

HDL-C, HDL-cholesterol

HTGL, hepatic triglyceride lipase

LCAT, lecithin:cholesterol acyltransferase

LDL, low density lipoproteins

TC, total cholesterol

Received September 14, 1987; accepted January 20, 1988. Correspondence and reprint requests Trudy M. Forte, Ph.D., Donner Laboratory, Lawrence Berkeley Laboratory, 1 Cyclotron Road, Berkeley, CA 94720.

Supported by NIH-NHLBI Program Project Grant HL 18574 and National Research Service Award Training Grant HL07279.
TG, triglyceride

VLDL, very low-density lipoproteins

The HDL is the major lipoprotein component in human cord blood. As in adult plasma, cord blood HDL is not a single homogeneous population of particles but consists of several distinct subclasses. Using nondenaturing gge, we have previously shown that HDL subclass distribution based on particle size is different in cord blood as compared with adult $\operatorname{HDL}(1,2)$. By the definition of Nichols et al. (3), adult HDL has five identifiable subclasses on gge, $\left(\mathrm{HDL}_{2 \mathrm{~b}}, \mathrm{HDL}_{2 \mathrm{a}}, \mathrm{HDL}_{3 \mathrm{a}}, \mathrm{HDL}_{3 \mathrm{~b}}\right.$, and $\left.\mathrm{HDL}_{3 \mathrm{c}}\right)_{\mathrm{gge}}$, and $\left(\mathrm{HDL}_{3 \mathrm{a}}\right)_{\mathrm{gge}}$ is the predominant component. Unlike adult HDL, normal cord blood has a paucity of particles in the $\left(\mathrm{HDL}_{3 \mathrm{a}}\right)_{\mathrm{gge}}$ region, and two distinct components within the $\left(\mathrm{HDL}_{2 \mathrm{a}}\right)_{\mathrm{gge}}$ region. This normal cord blood HDL subclass distribution correlates with plasma cholesterol levels $<85 \mathrm{mg} / \mathrm{dl}$ and TG levels $<65 \mathrm{mg} / \mathrm{dl}$ (2). In addition to the normal (gge) pattern, two other (gge) patterns have been identified in newborn infants and, in both instances, were associated with abnormal plasma lipid levels (2). One pattern, termed the $2 \mathrm{~b}$ (gge) pattern, is characterized by an increase in particles in the $\left(\mathrm{HDL}_{2 \mathrm{~b}}\right)_{\mathrm{gge}}$ subclass and is found most commonly in cord blood with elevated TC and HDL-C. The other pattern, termed the $3 \mathrm{~b}$ (gge) pattern, is characterized by a decrease of $\left(\mathrm{HDL}_{2 \mathrm{~b}}\right)_{\mathrm{gge}}$ and $\left(\mathrm{HDL}_{2 \mathrm{a}}\right)_{\mathrm{gge}}$ particles and by a predominance of particles in the $\left(\mathrm{HDL}_{3 \mathrm{~b}}\right)_{\mathrm{gge}}$ and $\left(\mathrm{HDL}_{3 \mathrm{c}}\right)_{\mathrm{gge}}$ subclasses. This pattern is mostly found in cord blood with elevated TG $(>65 \mathrm{mg} / \mathrm{dl})$ and low HDL-C. In all three cord blood patterns there is a paucity of material in the $\left(\mathrm{HDL}_{3 a}\right)_{\mathrm{gge}}$ region.

The HDL distribution in cord blood reflects mainly lipoprotein synthesis and metabolism by the liver with little or no contribution from intestinal cells. The conspicuous paucity of lipoproteins in the $\left(\mathrm{HDL}_{3 \mathrm{a}}\right)_{\mathrm{gge}}$ region in cord blood as compared to adults may be related to the lack of lipoproteins originating from the intestine. To determine what major changes in HDL subclass distribution are associated with enteral feeding during the early neonatal period, HDL particle size distribution was evaluated in premature newborns receiving enteral feedings.

\section{METHODS}

Population samples. Premature infants, born at a high risk perinatal center, with a birth weight $>1000 \mathrm{~g}$ and without major medical problems were eligible for this study. Informed consent was obtained from the parents. The research protocol was approved by the institutional review boards for human research at 
Children's Hospital, Oakland; Alta Bates Hospital, Berkeley; and the University of California, Berkeley, CA. Infants requiring total parenteral nutrition with intravenous fat were excluded from the study. Infants received intravenous glucose solution in the first few days of life. When clinically stable, feedings were started with maternal breast milk when available, and/or Similac Special Care $20 \mathrm{cal} / \mathrm{oz}$ or $24 \mathrm{cal} / \mathrm{oz}$ (Ross Laboratories, Columbus, $\mathrm{OH}$ ). No infant was exclusively breast-fed. Characteristics of the 16 infants enrolled in the study are shown in Table 1 .

Cord blood was obtained at delivery from 10 of the 16 patients. Venous blood was obtained while the infants were receiving enteral feedings between 6-14 days postnatally (sample A) and again at 17-32 days (sample B). Six infants were discharged before sample B was obtained. All samples were collected just before feeding into tubes containing EDTA $(1 \mathrm{mg} / \mathrm{ml})$ and refrigerated immediately. Inasmuch as prolonged fasting is poorly tolerated in premature infants, no attempt was made to obtain fasting samples. Blood samples were obtained 2 to $3 \mathrm{~h}$ after feeding, between 0800 and $1000 \mathrm{~h}$.

Red cells were separated from plasma by centrifugation at $4000 \times g$ for $20 \mathrm{~min}$ at $4^{\circ} \mathrm{C}$ and gentamicin $(0.1 \mathrm{mg} / \mathrm{ml})$, EDTA $(1 \mathrm{mg} / \mathrm{ml})$, parahydroxymercurosulfonic acid $(2 \mathrm{mM})$, and sodium azide $(0.4 \mathrm{mg} / \mathrm{ml})$ were added to the plasma.

Lipid levels. Plasma TG and TC were determined by enzymatic methods (TG, Gilford Diagnostics, Cleveland, OH; TC, Worthington Diagnostics, Freehold, NJ). HDL-C was isolated by the precipitation technique of Steele et al. (4). Briefly, heparin and $\mathrm{MnCl}_{2}$ were added to $0.5 \mathrm{ml}$ plasma to precipitate LDL and VLDL and incubated for $30 \mathrm{~min}$. After incubation, the samples were centrifuged for $30 \mathrm{~min}\left(1500 \times g\right.$ at $\left.4^{\circ} \mathrm{C}\right)$. The supernatant was then analyzed for cholesterol. Cholesterol values determined by the latter method agree well with HDL-C concentrations obtained from ultracentrifugally isolated HDL (1).

Lipoprotein isolation and gradient gel electrophoresis. Lipoproteins were isolated at density $1.21 \mathrm{~g} / \mathrm{ml}$ in a single ultracentrifugal step in a Beckman 40.3 rotor $\left(100,000 \times g\right.$ for $24 \mathrm{~h}$ at $4^{\circ}$ C) as described by Lindgren et al. (5), except that $2-\mathrm{ml}$ tubes were used and volumes adjusted accordingly.

The density $<1.21 \mathrm{~g} / \mathrm{ml}$ fractions were analyzed by nondenaturing polyacrylamide gradient gel electrophoresis to determine HDL size distribution. Electrophoresis was carried out on precast Pharmacia 4-30\% polyacrylamide slab gels (Pharmacia, Piscataway, NJ), according to the procedure of Nichols et al. (3). Reference proteins used to determine particle diameter consisted of thyroglobulin, apoferritin, lactate dehydrogenase, and bovine serum albumin. Gels were stained with Coomassie G-250 to identify protein peaks, and densitometric scans were obtained with a Transidyne RFT densitometer (Transidyne Corp., Ann Arbor, MI).

Changes in HDL subclass distribution as a function of enteral feeding were determined by measuring the relative optical density by the method previously described (2). The height of each peak and shoulder on densitometric scans was measured and its relative value calculated as a percentage of the total of all heights in the scan. This value constitutes the relative optical density of that particular protein band. If no peak or shoulder was present in a region, the relative optical density was considered to be 0 . The terms $\left(\mathrm{HDL}_{3 \mathrm{a}}\right)_{\mathrm{gge}},\left(\mathrm{HDL}_{3 \mathrm{~b}}\right)_{\mathrm{gge}}$, and $\left(\mathrm{HDL}_{3 \mathrm{c}}\right)_{\mathrm{gge}}$, according to the nomenclature of Nichols et al. (3), designate the smaller, more dense subclasses found within the ultracentrifugal $\mathrm{HDL}_{3}$ fraction (density $1.125-1.20 \mathrm{~g} / \mathrm{ml}$ ) from adult plasma, whereas the terms $\left(\mathrm{HDL}_{2 \mathrm{~b}}\right)_{\mathrm{gge}}$ and $\left(\mathrm{HDL}_{2 \mathrm{a}}\right)_{\mathrm{gge}}$ designate larger, less dense $\mathrm{HDL}$ subclasses within the $\mathrm{HDL}_{2}$ (density $1.063-1.125 \mathrm{~g} / \mathrm{ml}$ ) ultracentrifugal fraction. Inasmuch as normal cord blood has two peaks within the $\left(\mathrm{HDL}_{2 \mathrm{a}}\right)_{\mathrm{gge}}$ region $(2)$, these peaks are designated $\left(\mathrm{HDL}_{2 \mathrm{a} 1}\right)_{\mathrm{gge}}$ and $\left(\mathrm{HDL}_{2 \mathrm{a} 2}\right)_{\mathrm{gge}}$. Particle size intervals defining HDL subpopulations are: $\left(\mathrm{HDL}_{2 \mathrm{~b}}\right)_{\mathrm{gge}}, 12.9-9.7 \mathrm{~nm}$; $\left(\mathrm{HDL}_{2 \mathrm{a}}\right)_{\mathrm{gge}} 9.7-8.8 \mathrm{~nm}$; (HDL $\left.{ }_{3 \mathrm{a}}\right)_{\mathrm{gge}}, 8.8-8.2 \mathrm{~nm}$; (HDL $\mathrm{Hb}_{3 \mathrm{gge}}, 8.2-$ $7.8 \mathrm{~nm}$; and (HDL 3 c) gge, $7.8-7.2 \mathrm{~nm}(6)$.

Statistical method. The unpaired $t$ test was used to compare lipid values and relative optical densities.

\section{RESULTS}

Plasma lipid concentrations. Table 2 summarizes the TG, TC, and HDL-C levels at birth and after the onset of enteral feeding. Mean cord blood TC $(86 \pm 27 \mathrm{mg} / \mathrm{dl})$ was elevated as compared to normal term infants $(62.5 \mathrm{mg} / \mathrm{dl})(2)$. This is not unexpected since increased plasma cholesterol in premature infants has been previously reported (7-9). Cord blood TG levels of the infants in this study are comparable to those reported for normal term infants (2). After enteral feedings, both the mean TG and TC are significantly elevated at both sampling times compared with cord blood (Table 2). HDL-C also increases with feeding and is significantly higher in the second feeding period (Table 2 ).

$H D L$ subclass distribution. Herein three distinct cord blood HDL gradient gel patterns were noted and representative scans of the three patterns are seen in Figure $1 A-C$. For comparison, scans of normal male and female adult HDL are also included (Fig. $1 D$ ). Figure $1 A$ is the pattern that we previously described as the normal (gge) pattern, generally associated with normal term infants, which occurred in three infants. This pattern shows major peaks in the $\left(\mathrm{HDL}_{2 \mathrm{~b}}\right)_{\mathrm{gge}},\left(\mathrm{HDL}_{2 \mathrm{a}}\right)_{\mathrm{gge}}$, and $\left(\mathrm{HDL}_{3 \mathrm{~b}}\right)_{\mathrm{gge}}$ regions and a paucity of material in the $\left(\mathrm{HDL}_{3 \mathrm{a}}\right)_{\mathrm{gge}}$ region. The $\left(\mathrm{HDL}_{2 \mathrm{a}}\right)_{\mathrm{gge}}$ region frequently contains two peaks $\left(\mathrm{HDL}_{2 \mathrm{a} 1}\right)_{\mathrm{gge}}$ and $\left(\mathrm{HDL}_{2 \mathrm{a} 2}\right)_{\mathrm{gge}}$. The scan in Figure $1 B$ shows the $2 \mathrm{~b}$ (gge) pattern where characteristically there is a very pronounced $\left(\mathrm{HDL}_{2 \mathrm{~b}}\right)_{\mathrm{gge}}$ peak and a minimum in $\left(\mathrm{HDL}_{3 \mathrm{a}}\right)_{\mathrm{gge}}$; this pattern was seen in five cord blood samples. The $3 \mathrm{~b}$ (gge) pattern represented in Figure $1 C$ (two cord blood samples) is characterized by a shift of particles to the smaller, more dense $\left(\mathrm{HDL}_{3 \mathrm{~b}}\right)_{\mathrm{gge}}$ region but a scarcity of $\left(\mathrm{HDL}_{3 \mathrm{a}}\right)_{\mathrm{gge}}$ particles is clearly evident. These three patterns have been described in detail elsewhere (2). In contrast to cord blood, HDL from normal male and female plasma have a predominant peak in the $\left(\mathrm{HDL}_{3 \mathrm{a}}\right)_{\mathrm{gge}}$ region (Fig. $\left.1 D\right)$. Adult $\mathrm{HDL}$ subclass distri-

Table 2. Mean values ( $\pm S D$ ) of $T G, T C$, and $H D L-C$ for cord blood and samples $A$ and $B$

\begin{tabular}{lcccl}
\hline Sample & $n$ & $\begin{array}{c}\text { TG } \\
(\mathrm{mg} / \mathrm{dl})\end{array}$ & $\begin{array}{c}\text { TC }(\mathrm{mg} / \\
\mathrm{dl})\end{array}$ & $\begin{array}{c}\text { HDL-C } \\
(\mathrm{mg} / \mathrm{dl})\end{array}$ \\
\hline Cord blood & 10 & $34 \pm 11$ & $86 \pm 27$ & $38 \pm 13$ \\
A & 16 & $159 \pm 82^{*}$ & $118 \pm 21 \dagger$ & $43 \pm 15$ \\
B & 10 & $120 \pm 26^{*}$ & $112 \pm 10 \ddagger$ & $54 \pm 12 \S$ \\
\hline
\end{tabular}

${ }^{*} p<0.0001, \dagger p<0.003, \ddagger p<0.03, \S p<0.02$ for comparison of means with cord blood based on unpaired $t$ test.

Table 1. Characteristics of study population

\begin{tabular}{|c|c|c|c|c|c|c|c|c|}
\hline & $\begin{array}{c}\text { Birth wt } \\
(\mathrm{g})\end{array}$ & $\begin{array}{c}\text { Gestational } \\
\text { age } \\
\text { (wk) }\end{array}$ & $\begin{array}{c}\text { Age } \\
\text { (days) }\end{array}$ & $\begin{array}{c}\text { Sample A } \\
\text { wt } \\
\text { (g) }\end{array}$ & $\begin{array}{c}\text { Cal } \\
\text { (kcal/kg/day) }\end{array}$ & $\begin{array}{c}\text { Age } \\
\text { (days) }\end{array}$ & $\begin{array}{c}\text { Sample B } \\
\text { wt } \\
(\mathrm{g})\end{array}$ & $\begin{array}{c}\mathrm{Cal} \\
(\mathrm{kcal} / \mathrm{kg} / \text { day })\end{array}$ \\
\hline Mean & 1608 & 32.7 & 9.6 & 1602 & 104.5 & 23.1 & 1965 & 123.2 \\
\hline SD & 196 & 1.6 & 2.6 & 244 & 17.6 & 4.9 & 100 & 25.0 \\
\hline Range & $1170-1930$ & $30-36$ & $6-14$ & $1270-2250$ & $77-150$ & $17-32$ & $1810-2140$ & $95-171$ \\
\hline$n$ & 16 & & 16 & & & 10 & & \\
\hline
\end{tabular}


A
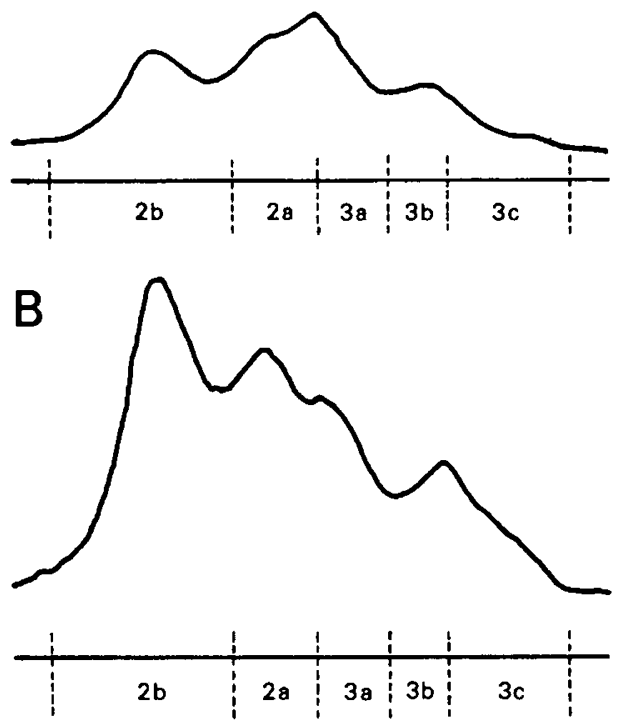

C
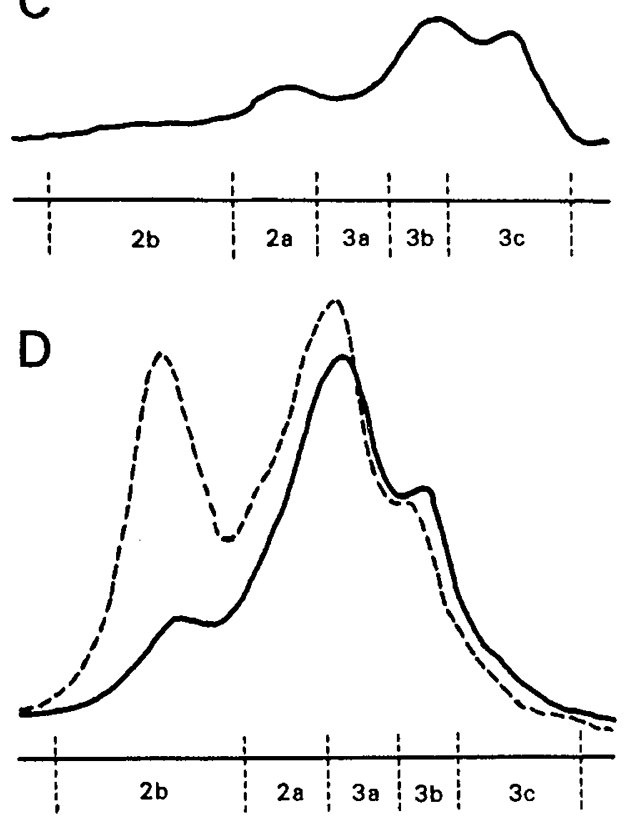

Fig. 1. Representative scans of different types of nondenaturing gradient gel profiles seen in cord blood of premature infants: $A$, normal gge pattern; $B, 2 \mathrm{~b}$ (gge) pattern, distinguished by a pronounced elevation of the $\left(\mathrm{HDL}_{2 \mathrm{~b}}\right)_{\mathrm{gse}}$ peak; $C, 3 \mathrm{~b}$ (gge) pattern, characterized by a deficiency of $\mathrm{HDL}_{2 \mathrm{~b}}$ particles and a preponderance of $\left(\mathrm{HDL}_{3 \mathrm{~b}}\right)_{\text {gge }}$ particles; $D$, adult patterns, (-) male, (----) female. Note that the adult HDL pattern possesses a pronounced peak in the $\left(\mathrm{HDL}_{3 \mathrm{a}}\right)_{\text {gge }}$ region; however, cord blood samples do not have a peak in this region. The HDL subclass regions shown on the $\mathrm{x}$-axis are based on the distributions obtained from 194 normal adults as previously reported by this laboratory (6). The latter study showed that there was little variation in peak positions for HDL subclasses where the SD and coefficients of variation for individual measurements were as follows: $\left(\mathrm{HDL}_{2 \mathrm{~b}}\right)_{\mathrm{gge}} \pm 0.003,0.49 \%$; $\left(\mathrm{HDL}_{2 \mathrm{a}}\right)_{\mathrm{gge}}$, $\pm 0.012,1.69 \%\left(\mathrm{HDL}_{3 \mathrm{a}}\right)_{\mathrm{gge}}, \pm 0.005,0.68 \%$; $\left(\mathrm{HDL}_{3 \mathrm{~b}}\right)_{\mathrm{gge}}, \pm 0.007,0.8 \%$; and $\left(\mathrm{HDL}_{3 \mathrm{c}}\right)_{\mathrm{gse}}, \pm 0.005,0.5 \%$. bution also shows a marked difference between males and females in that the latter frequently have a pronounced peak in the $\left(\mathrm{HDL}_{2 \mathrm{~b}}\right)_{\mathrm{gge}}$ region. Gradient gel scans of $\mathrm{HDL}$ from the 16 subjects in this study are summarized in Figure 2. The most notable feature of cord blood and the postnatal samples is the general lack of a peak in the $\left(\mathrm{HDL}_{3 \mathrm{a}}\right)_{\text {gge }}$ region. Cord bloods exhibiting a pronounced $\left(\mathrm{HDL}_{2 \mathrm{~b}}\right)_{\mathrm{gge}}$ peak tend to have elevated HDL-C levels ( $46.4 \pm 5.5 \mathrm{mg} / \mathrm{dl}, n=5$ ) as compared with the infants with the normal pattern $(36.0 \pm 10.2 \mathrm{mg} / \mathrm{dl}, n=3)$. The two cord blood samples with the (HDL $\left.{ }_{3 \mathrm{~b}}\right)_{\mathrm{gge}}$ pattern (Fig. $2, C B$ 12 and 13) have low HDL-C (18 and $19 \mathrm{mg} / \mathrm{dl}$, respectively). Cord blood samples were obtained from infants with gestational

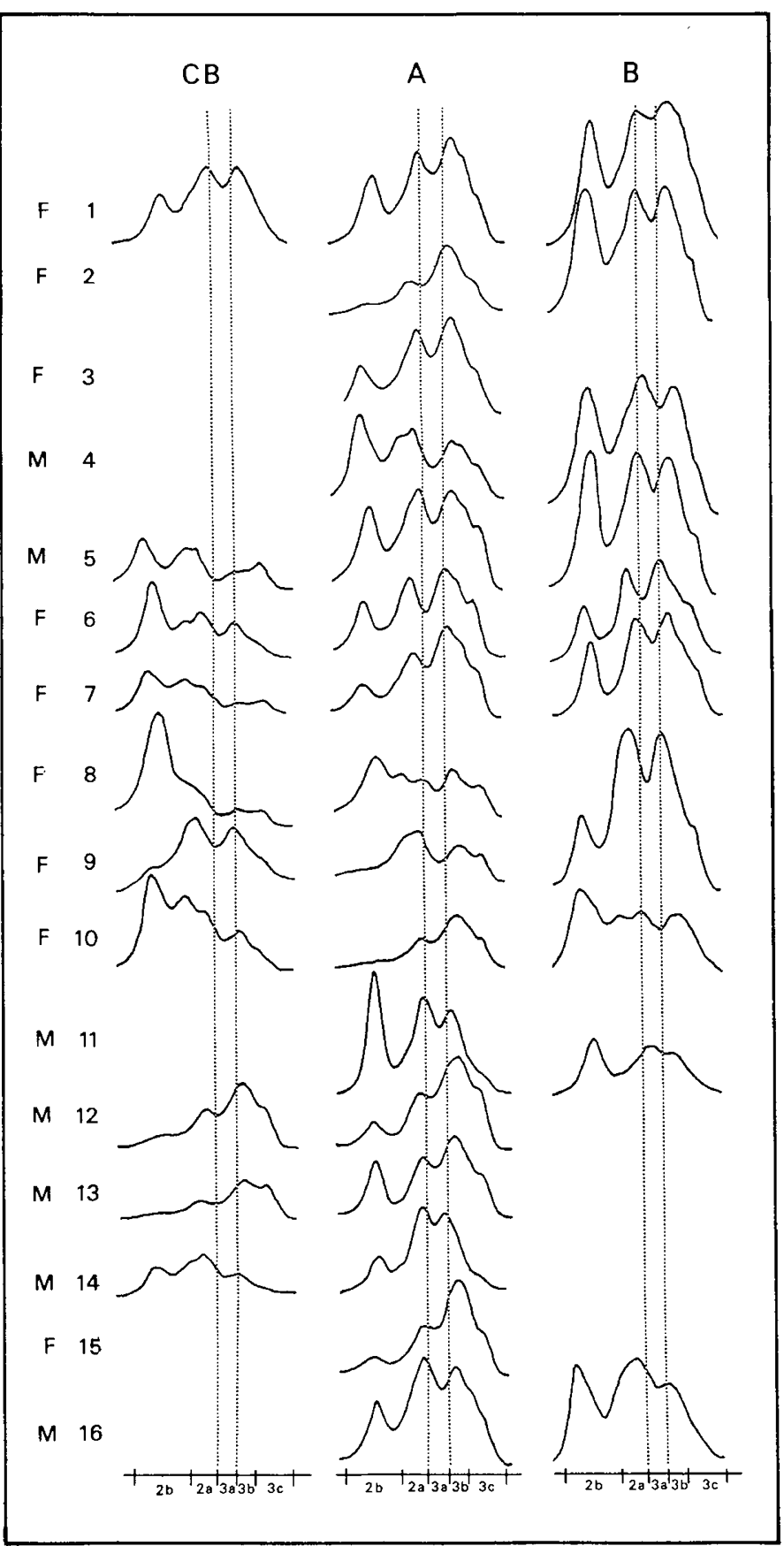

Fig. 2. Scans of HDL gradient gel patterns of all subjects in the study. Only 10 cord blood $(C B)$ samples were available for analysis. Samples in $A$ were obtained 6-14 days postnatally, whereas samples in $B$ were obtained at 17-32 days. Only 10 samples of the latter were available for analysis. The broken line indicates the $\left(\mathrm{HDL}_{3 a}\right)_{8 g e}$ region. The sex of each subject is noted: female $(F)$ and male $(M)$. 
ages of 31 to $36 \mathrm{wk}$ and there appeared to be no association between age and HDL patterns, although our sample size is small. Samples obtained within 2 wk of initiation of the enteral feeding regimen (sample A) show considerable variability in pattern profiles (Figure $2 A$ ). Overall, the patterns tend to approximate those of cord blood rather than adult patterns (compare Fig. $1 D$ ). The B samples obtained 17-32 days after birth are more uniform from subject to subject and HDL subclasses are relatively evenly distributed among the $\left(\mathrm{HDL}_{2 \mathrm{~b}}\right)_{\mathrm{gge}}$, $\left(\mathrm{HDL}_{2 \mathrm{a}}\right)_{\mathrm{gge}}$, and $\left(\mathrm{HDL}_{3 \mathrm{~b}}\right)_{\mathrm{gge}}$ regions in a majority of samples. In postnatal samples, particularly those of the B series, the $\left(\mathrm{HDL}_{2 \mathrm{~b}}\right)_{\mathrm{gge}}$ region has a distinct peak which, relative to other HDL components, looks somewhat similar to that seen in adult females (compare Fig. 1D). A second pronounced peak is also found in the $\left(\mathrm{HDL}_{2 \mathrm{a}}\right)_{\mathrm{gge}}$ region after feeding; in some instances there are two peaks or a shoulder and a peak in this region. When only one peak is seen, it is found close to or on the border of the $\left(\mathrm{HDL}_{3 \mathrm{a}}\right)_{\mathrm{gge}}$ region. Only two samples (Fig. 2, $4 \mathrm{~B}$ and $11 \mathrm{~B}$ ) have a peak that falls within the $\left(\mathrm{HDL}_{3 \mathrm{a}}\right)_{\mathrm{gge}}$ region; however, no sample contains a peak in both the $\left(\mathrm{HDL}_{2 \mathrm{a}}\right)_{\mathrm{gge}}$ and $\left(\mathrm{HDL}_{3 \mathrm{a}}\right)_{\mathrm{gge}}$ regions. In postnatal $A$ and $B$ samples, the $\left(\mathrm{HDL}_{3 \mathrm{~b}}\right)_{\text {gge }}$ region contains a pronounced peak; the $\left(\mathrm{HDL}_{3 \mathrm{c}}\right)_{\mathrm{gge}}$ region is relatively enriched and in some samples two components termed peak 1 and 2 in Table 3 are noted.

In Figure 2 cord blood samples 5 and 6 are scans of dizygotic twins where the former is a male infant and the latter a female. Both cord blood profiles are clearly $2 \mathrm{~b}$ (gge) patterns and the responses to enteral feedings are quite similar. No difference is noted between male and female infants in postnatal HDL subclass distribution in response to enteral feeding.

The mean relative optical densities of HDL subclasses in Figure 2 as a function of sample time were analyzed by the unpaired $t$ test (Table 3 ). In the postnatal samples there was a decrease compared with cord blood in the relative intensity of the $\left(\mathrm{HDL}_{2 \mathrm{a} 1}\right)_{\mathrm{gge}}$ component of both samples $\mathrm{A}$ and $\mathrm{B}$ which reached statistical significance in sample $\mathrm{A}(p<0.05)$. Increases are seen in the $\left(\mathrm{HDL}_{3 \mathrm{~b}}\right)_{\mathrm{gge}}$ region of samples $\mathrm{A}$ and $\mathrm{B}$ compared with cord blood and were significantly elevated in the A sample. The intensity of the smallest sized $\mathrm{HDL}$ component $\left(\left(\mathrm{HDL}_{3 c}\right.\right.$ peak 2) increases with the onset of feeding and is significantly elevated in sample A $(p<0.02)$.

\section{DISCUSSION}

Cord blood HDL subclass distribution in general is characterized by the absence of a peak in the $\left(\mathrm{HDL}_{3 \mathrm{a}}\right)_{\mathrm{gge}}$ subclass region and clearly this is the case with the premature infants examined herein. The metabolic reason for the apparent lack of a peak in the region, where in adults there is a prominent $\mathrm{HDL}_{3 a}$ component, is not well understood. Inasmuch as the normal distribution of adult HDL is believed to be linked with TG metabolism (1015) and the infant at birth has extremely low plasma $T G$, the $\left(\mathrm{HDL}_{3 \mathrm{a}}\right)_{\mathrm{gge}}$ deficiency in cord blood might be explained on the basis of decreased availability of TG-rich particles. However, we found that the influx of dietary TG in the early postnatal period of premature infants did not lead to the rapid appearance of a peak in the $\left(\mathrm{HDL}_{3 \mathrm{a}}\right)_{\mathrm{gge}}$ region. This suggests that a deficiency of
TG-rich particles alone cannot explain the relative paucity of $\left(\mathrm{HDL}_{3 \mathrm{a}}\right)_{\mathrm{gge}}$ particles in the infant at birth. It is noteworthy that two of the infants on oral feeding for 17-32 days (B samples) did show the presence of a peak in this region. More importantly, with enteral feeding there was a disappearance of $\left(\mathrm{HDL}_{2 \mathrm{a}}\right)_{\mathrm{gge}}$ components and a shift of the $\left(\mathrm{HDL}_{2 \mathrm{a} 2}\right)_{\mathrm{gge}}$ toward slightly smaller diameter particles in the interface region between $\left(\mathrm{HDL}_{2 \mathrm{a} 2}\right)_{\mathrm{gge}}$ and $\left(\mathrm{HDL}_{3 \mathrm{a}}\right)_{\mathrm{gge}}$. This trend suggests that maturation of the HDL subclass distribution is a gradual one.

Development of the normal adult HDL subclass distribution is very complex and several metabolic factors are known to play a role in altering HDL subclass distribution. Two plasma enzymes, LCAT and HTGL are crucial in the metabolism of HDL. LCAT catalyzes the formation of CE from FC and phospholipid, and its preferred substrate is the smallest, densest HDL (16). Increased content of CE core in HDL as a result of LCAT activity leads to the formation of larger, less dense particles, i.e. $\mathrm{HDL}_{2 \mathrm{~b}}$. $\mathrm{CE}$ in $\mathrm{HDL}_{2 \mathrm{~b}}$ particles is likely to be exchanged for TG in less dense lipoproteins, such as VLDL and LDL, through the action of plasma CETP (17). TG transferred to the $\mathrm{HDL}_{2 b}$ subclass can be hydrolyzed by HTGL, thus regenerating a smaller, denser particle and decreasing the levels of the large, less dense $\mathrm{HDL}_{2 \mathrm{~b}}$. Profiles seen in postnatal infants during the second sampling period (B sample) consistently showed a pronounced $\left(\mathrm{HDL}_{2 \mathrm{~b}}\right)_{\mathrm{gge}}$ peak reminiscent of the pattern noted in normal adult premenopausal females. In the adult population, it has been suggested that estrogen reduces HTGL activity with the resultant rise in the $\mathrm{HDL}_{2 \mathrm{~b}}$ component (18); this could account for the pronounced $\left(\mathrm{HDL}_{2 \mathrm{~b}}\right)_{\mathrm{gge}}$ peak in premenopausal women. Although speculative, hormone levels in the postnatal premature infant may influence HTGL activity and, with it, HDL subclass distribution.

In adults a negative correlation has been found between HTGL and $\mathrm{HDL}_{2}$ levels $(19,20)$. Recently, Chang et al. (21) have shown that hypertriglyceridemia is associated with a decrease in plasma HDL-C concentrations and a shift in HDL distribution from larger $\mathrm{HDL}_{3 \mathrm{a}}$ particles to smaller $\mathrm{HDL}_{3 b}$ particles. Two of the present cord blood samples had the $\left(\mathrm{HDL}_{3 \mathrm{~b}}\right)_{\mathrm{gge}}$ pattern and, with it, low HDL-C levels. However, in both instances, TG concentrations were normal, suggesting that the relationships between TG and HDL size and HDL-C concentration seen in adult hypertriglyceridemia do not necessarily hold for the neonate. A possible mechanism for the formation of smaller HDL in the face of normal TG concentrations is that HTGL in these infants may be functioning very efficiently. Inasmuch as HTGL hydrolyzes phospholipids in addition to $\mathrm{TG}$, this enzyme in some instances may play a crucial role in determining the predominance of small, dense HDL such as $\mathrm{HDL}_{3 \mathrm{~b}}$. Rovamo et al. (22) have shown that plasmas of neonates possess both lipoprotein lipase and HTGL where the latter accounts for approximately $77 \%$ of the total lipolytic activity.

Inasmuch as the enzyme LCAT is functionally important in determining HDL composition and hence its distribution, low LCAT activity during the early postnatal period might be a contributing factor in the persistence of the unusual HDL subclass distribution noted in our study. LCAT activity in the newborn is approximately $50 \%$ that of adults $(23,24)$. In the

Table 3. Mean ( $\pm S D$ ) relative optical density of HDL subclasses according to sample time and peak location within (HDL) gge distribution

Location of peak in HDL scan

\begin{tabular}{|c|c|c|c|c|c|c|}
\hline \multirow[b]{2}{*}{$2 b$} & \multirow[b]{2}{*}{$2 a_{1}$} & \multirow[b]{2}{*}{$2 a_{2}$} & \multirow[b]{2}{*}{$3 a$} & \multirow[b]{2}{*}{$3 b$} & \multicolumn{2}{|c|}{$3 \mathrm{c}$} \\
\hline & & & & & Peak 1 & Peak 2 \\
\hline $24.0 \pm 13.0$ & $14.4 \pm 12.6$ & $24.7 \pm 6.0$ & & $22.2 \pm 11.0$ & $8.1 \pm 13.5$ & $6.1 \pm 7.0$ \\
\hline $18.1 \pm 9.0$ & $3.9 \pm 8.6^{*}$ & $25.6 \pm 5.1$ & & $30.0 \pm 8.4 \uparrow$ & $9.3 \pm 11.1$ & $13.2 \pm 7.9 \ddagger$ \\
\hline $26.0 \pm 5.5$ & $5.8 \pm 9.6$ & $22.0 \pm 11.6$ & $6.5 \pm 13.0$ & $27.4 \pm 4.7$ & $1.9 \pm 6.0$ & $10.5 \pm 7.4$ \\
\hline
\end{tabular}

* $p<0.02, \dagger p<0.05, \ddagger p<0.03$ for comparison of means with cord blood based on unpaired $t$ test. 
normal term infants, $\mathrm{TC}$ is also low; therefore, one might expect normal CE/FC ratios, and this is indeed the case (24). However, it has recently been demonstrated that there is a positive correlation between fetal age and LCAT activity (24). On the basis of the $\mathrm{CE} / \mathrm{FC}$ ratio Jain (24) found that infants with gestational ages less than $32 \mathrm{wk}$ had significantly lower LCAT activity (CE/ FC ratio $0.49-1.51$ ) than older premature infants (CE/FC ratio of $1.83-1.96$ for 32 - to 41 -wk-old infants whereas the adult ratio was 2.1) (24). Herein nine of the 16 infants were 32 wk or less in gestational age; therefore, one cannot discount the possibility that low LCAT activity during the early postnatal period may-be a contributing factor to the persistence of a valley in the $\left(\mathrm{HDL}_{3 \mathrm{a}}\right)_{\mathrm{gge}}$ region.

apo AI associated with HDL is a cofactor required for activation of LCAT. The concentration of this protein in cord blood is approximately one-half to two-thirds that of adults (25-28). In adult plasma, the $\left(\mathrm{HDL}_{3 \mathrm{a}}\right)_{\mathrm{gge}}$ region is characterized by the presence of a large proportion of particles containing apo AI without apo AII (29). Because it is possible that the unusual distribution of HDL subclasses in our premature infants on enteral nutrition is related to low levels of plasma apo AI, preliminary studies quantitating apo AI were carried out on five infants. Apo AI concentrations were determined by single radial immunodiffusion kits (Tago Inc., Burlingame, $\mathrm{CA}$ ) and were found to be within normal adult values during the second feeding period (63 $\pm 19 \mathrm{mg} / \mathrm{dl}$ at birth to $148 \pm 21 \mathrm{mg} / \mathrm{dl}$ at sample B). The latter is consistent with reported plasma apo AI values for normal infants 30 days after birth (30). It is unlikely that the paucity of $\left(\mathrm{HDL}_{3 \mathrm{a}}\right)_{\mathrm{gge}}$ particles is attributable to low concentrations of apo AI.

In summary, the development of adult-like plasma HDL subclass distribution in human neonates is very complex. Our studies indicate that low plasma TG concentrations per se are not directly responsible for the paucity of $\left(\mathrm{HDL}_{3 a}\right)_{\mathrm{gge}}$ particles because, with feeding, TG concentrations are augmented. It is probable that several undefined factors including plasma LCAT, lipoprotein lipase, and hepatic TG lipase levels, lipid exchange protein concentrations, and hormonal status play important roles in the maturation of HDL subclasses. Future studies are clearly required to understand the contribution of each of these factors, alone or in concert, to development of the mature HDL pattern.

Acknowledgments. The authors thank Dr. Melissa A. Austin for her helpful discussion of the study, Janet Selmek-Halsey, and Robert Nordhausen for their excellent technical assistance, and Mary Lou Kurtz for preparation of the manuscript.

\section{REFERENCES}

1. Davis PA, Forte TM, Nichols AV, Blum CB 1983 Umbilical cord blood lipoproteins: isolation and characterization of high density lipoproteins. Arteriosclerosis 3:357-365

2. Genzel-Boroviczény O, Forte TM, Austin MA 1986 High density lipoprotein subclass distribution and human cord blood lipid levels. Pediatr Res 20:487491

3. Nichols AV, Blanche PJ, Gong EL 1983 Gradient gel electrophoresis of human plasma high density lipoproteins. In: Lewis LA (ed) CRC Handbook of Electrophoresis, Vol III. CRC Press, Inc., Boca Raton, FL, pp 29-47

4. Steele BW, Koehler DF, Azar MM, Blaszkowski TP, Kuba Kanta, Dempsey ME 1976 Enzymatic determinations of cholesterol in high density lipoprotein fractions prepared by a precipitation technique. Clin Chem 22:98-101

5. Lindgren FT, Jensen LC, Hatch FT 1972 The isolation and quantitative analysis of serum lipoproteins. In: Nelson GJ (ed) Blood Lipids and Lipoproteins. John Wiley-Interscience, New York, pp 181-274

6. Blanche PJ, Gong EL, Forte TM, Nichols AV 1981 Characterization of human high density lipoproteins by gradient gel electrophoresis. Biochim Biophys Acta 665:408-419

7. Hardell LI 1981 Serum lipids and lipoproteins at birth based on a study of 2815 newborn infants: II. Relations between materno-foetal factors and the concentrations of triglycerides and cholesterol. Acta Pediatr Scand [Suppl] 285:11-20

8. Lane DM, McConathy WJ 1983 Factors affecting the lipid and apolipoprotein levels of cord sera. Pediatr Res 17:83-91

9. Andersen GE, Friis-Hansen B 1978 Hypercholesterolemia in the newborn: occurrence after antepartum treatment with betamethasone-phenobarbitalritodrine for the prevention of the respiratory distress syndrome. Pediatrics 62:8-12

10. Nichols AV, Smith L 1965 Effect of very low density lipoproteins on lipid transfer in incubated serum. J Lipid Res 6:206-210

11. Krauss RM 1982 Regulation of high density lipoprotein levels. Med Clin North Am 66:403-430

12. Deckelbaum R, Eisenberg S, Oschry Y, Blum C 1982 Abnormal high density lipoproteins in abetalipoproteinemia: relevance to normal HDL formation. J Lipid Res 23:1274-1283

13. Hopkins GJ, Barter PJ 1980 Transfers of esterified cholesterol and triglyceride between high density and very low density lipoproteins: in vitro studies of rabbits and humans. Metabolism 29:546-550

14. Marcel YL, Vezina C, Teng B, Sniderman A 1980 Transfer of cholesterol esters between human high density lipoproteins and triglyceride-rich lipoproteins controlled by a plasma protein factor. Atherosclerosis 35:127-133

15. Chang LBF, Hopkins GJ, Barter PJ 1985 Particle size distribution of high density lipoproteins as a function of plasma triglyceride concentration in human subjects. Atherosclerosis 56:61-70

16. Chen C, Applegate K, King WC, Glomset JA, Norum KR, Gjone E 1984 A study of the small spherical high density lipoproteins of patients afflicted with familial lecithin:cholesterol acyltransferase deficiency. J Lipid Res 25:269-282

17. Barter PJ, Hopkins GJ, Ying CH 1987 The role of lipid transfer proteins in plasma lipoprotein metabolism. Am Heart J 113:538-542

18. Weinberg RB 1987 Lipoprotein metabolism: hormonal regulation. Hosp Pract 26:125-145

19. Kuusi T, Saarinen P, Nikkila EA 1980 Evidence for the role of hepatic endothelial lipase in the metabolism of plasma high density lipoprotein in $_{2}$ man. Atherosclerosis 36:589-593

20. Breckenridge WC, Little JA, Alaupovic P, Wang CS, Kuksis A, Kakis G, Lindgren F, Gardiner G 1982 Lipoprotein abnormalities associated with a familial deficiency of hepatic lipase. Atherosclerosis 45:161-179

21. Chang LBF, Hopkins GJ, Barter PJ 1985 Particle size distribution of high density lipoproteins as a function of plasma triglyceride concentration in human subjects. Atherosclerosis 56:61-70

22. Rovamo L, Taskinen MR, Kuusi T, Nikkila EA, Ehnholm C, Raivio KO 1984 Postheparin plasma lipase activities and plasma lipoproteins in newborn infants. Pediatr Res 18:642-647

23. Lacko AG, Rutenberg HL, Soloff LA 1972 On the rate of cholesterol esterification in cord blood serum. Lipids 7:426-429

24. Jain SK 1985 Prematurity and lecithin:cholesterol acyltransferase deficiency in newborn infants. Pediatr Res 19:58-60

25. McConathy WJ, Lane DM 1980 Studies on the apolipoproteins and lipoproteins in cord blood serum. Pediatr Res 14:757-761

26. Stozicky F, Slaby P, Volenikova L 1982 The pattern of major serum apolipoproteins during the early neonatal period. Acta Pediatr Scand 71:239-241

27. Rosseneu M, Van Biervliet JP, Bury J, Vinaimont N 1983 Isolation and characterization of lipoprotein profiles in newborns by density gradient ultracentrifugation. Pediatr Res 17:788-794

28. Strobl W, Widhalm K, Kostner G, Pollak A 1983 Serum apolipoproteins and lipoprotein (a) during the first week of life. Acta Pediatr Scand 72:505-509

29. Nichols AV, Gong EL, Blanche PJ, Forte TM, Shore VG 1987 Origin and heterogeneity of HDL subspecies. In: Lippel K (ed) Proceedings of the Workshop on Lipoprotein Heterogeneity. NIH Publication 87-2646, Bethesda, MD, pp 331-340

30. Van Biervliet JP, Vinaimont N, Caster H, Vercaemst R, Rosseneu M 1981 Plasma apoprotein and lipid patterns in newborns: influence of nutritional factors. Acta Pediatr Scand 70:851-856 